\title{
The discussion of the environmental impacts cost about the progress of power station
}

\author{
CHEN Wen ${ }^{1}$, YAN Tao $^{1, \mathrm{a}}$, CAI Wen ${ }^{1}$, Yang Hong-yan $^{2}$, WAN Zhong-hai ${ }^{1}$ \\ ${ }^{1}$ State Grid JiangXi Electric Power Research Institute, Nanchang 330096,Jiangxi Province,China \\ ${ }^{2}$ Shanghai Pengken Energy Technology Co.LTD, Shanghai 200090,China
}

\begin{abstract}
The key in the life cycle assessment is how to measure the environmental impacts. In this paper the environmental impacts of power station was measured by the money. Based on the statistic data in all country the environmental impacts cost of power station was concluded, which was combined with the inventory analysis of power station and applied the results of the environmental economics in our country. On this result, it can be further combined with the conventional technical and economic analysis of the power station, which lays a solid foundation for the comprehensive evaluation of TEE (technology, economy and environment) of the production process of the power station.
\end{abstract}

\section{Introduction}

The basic idea of the LCA method is the concept of system analysis. That is to say, combined with the feasibility analysis of the technical economy, the positive and negative benefits of a technological process can be quantified when the production (or activity, service) of a certain technology or product is regarded as a link in the organic system. ${ }^{[1]} \mathrm{A}$ key issue in this process is how to measure the environmental impact and how to combine the environmental impact with the technical and economic evaluation of production technology to get the comprehensive evaluation result. In the research of foreign scholars, especially the analysis of the environmental impact of the energy production process, more and more research tend to use the method of environmental economics to monetize the environmental impact and directly link with the conventional technical economic analysis. However, in the domestic research, it is more to adopt the classification and quantification, expert appraisal and model estimation, the subjective influence factors are greater. In this paper, the monetization method will be used to analyze the environmental impact of the power plant production process in China.

\section{Analysis scope of power station LCA}

The research object of the paper is the production process of power station. Therefore, the analysis scope of LCA is determined by energy transfer and conversion process in power station. The upstream production process of energy recalls the mining and transportation of raw materials (coal), while other production processes (such as the manufacture of transportation equipment and mining equipment, etc.) that have little to do with the power generation system are not considered. At the same time, the environmental impact of coal during transportation is mainly dust pollution, which is a minor environmental impact compared with the environmental impact caused by coal in the process of mining and power station production. So this during is also ignored in the analysis. According to the concept of life cycle analysis, a complete range of electric energy life cycle includes not only the primary energy production, transportation and power generation processes but also the downstream production processes such as distribution and transmission, and the final use of electricity, as shown in Figure 1.

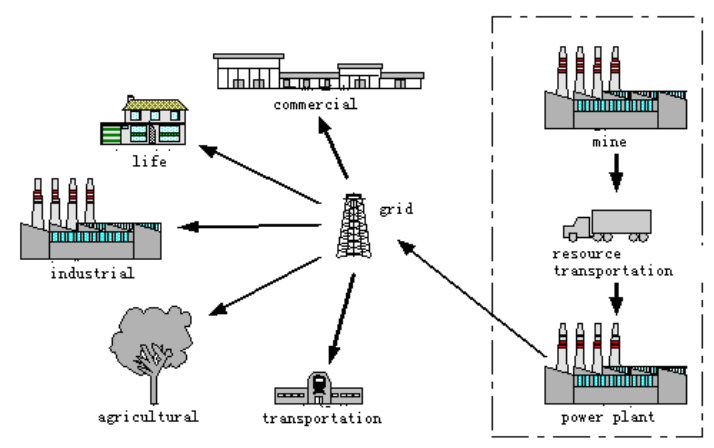

Figure 1 Life cycle diagram of electrical energy

The purpose of this paper is to evaluate power generation technology, the core problem is the power generation process, and downstream production process as well as the electrical energy end-use process for any kind of power generation process is the same. So the downstream production process and the use of electricity eventually is not included in the LCA analysis in this paper. In the study of Margaret K. Mann ${ }^{[1]}$, Levy ${ }^{[2]}$, etc., the environmental impact costs of the materials (mainly steel) consumed during the construction of the power

*Corresponding author: ${ }^{a}$ author@e-mail.org 
station were also taken into consideration. But due to the lack of environmental impacts data of the steel production process in China, the environmental impact of the power plant construction materials is not considered in the LCA analysis of this paper. In Margaret K. Mann's research a distinctive feature is that the assessment of environmental emissions and energy utilization and resource consumption per year of biomass gasification combined power generation system includes the process from construction and operation to final shutdown. The result was the actual value of the process's impact on the given year. For a long production cycle of raw materials system (text in the wood growth cycle was 7 years), the use of such analysis is of great significance. However, for coal-fired power stations, the production of coal could be synchronized with the power generation process, and the method of year-by-year analysis did not have many advantages. Hence, this paper analyzed the rated conditions of a normal production process of a conventional coal power station, and the results are the average of the environmental impact of the power station production process.

\section{Emission list}

It can be seen from the above that the environmental factors to be considered in the production of a conventional coal-fired power plant from fuel production to the final generation of electricity include: $\mathrm{O} 2, \mathrm{CO} 2$, NOx, dust, ash and the heat lost to the environment, upstream production Land collapse and coal gangue caused during the process. According to the data and methods provided in reference [3], the environmental impact factors of conventional pulverized coal power stations could be obtained as shown in Table 1.

Table 1 The environmental impact of electric energy production

\begin{tabular}{|c|c|c|c|c|}
\hline \multicolumn{2}{|c|}{ Production processes } & $\begin{array}{c}\text { Impact } \\
\text { factors }\end{array}$ & units & Quantity \\
\hline \multicolumn{2}{|c|}{ coal mining } & $\begin{array}{c}\text { Land } \\
\text { collapse }\end{array}$ & $\mathrm{m}^{2} / \mathrm{kW} . \mathrm{h}$ & $0.9875 \times 10^{-3}$ \\
\cline { 3 - 5 } & Coal gangue & $\mathrm{kg} / \mathrm{kW} . \mathrm{h}$ & 0.0974 \\
\hline \multirow{2}{*}{$\begin{array}{c}\text { Power } \\
\text { generation } \\
\text { process }\end{array}$} & \multirow{2}{*}{$\begin{array}{c}\text { Boiler } \\
\text { smoke }\end{array}$} & $\mathrm{CO}_{2}$ & $\mathrm{~kg} / \mathrm{kW} . \mathrm{h}$ & 0.7690 \\
\cline { 3 - 5 } & $\mathrm{SO}_{2}$ & $\mathrm{~kg} / \mathrm{kW} . \mathrm{h}$ & $31.43 \times 10^{-3}$ \\
\cline { 3 - 5 } & $\begin{array}{c}\text { Ash } \\
\text { residue }\end{array}$ & Solid Waste & $\mathrm{kg} / \mathrm{kW} . \mathrm{h}$ & $2.857 \times 10^{-3}$ \\
\cline { 3 - 5 } & $\mathrm{kg} / \mathrm{kW} . \mathrm{h}$ & 0.02857 \\
\hline
\end{tabular}

\section{Economic Analysis of Power Station Environmental Impact}

In the existing plant environmental costs, only the damage caused by exhaust gas is generally considered, and the impact of pollutants on human health and crop production are usually estimated. Due to the great differences in population distribution, human capital, social welfare, technological development and agricultural production in all regions and countries, the calculation results obtained by different countries or different regions will be very different. In addition, because of the imparity of the pollution damage function chosen by different researchers and the scope of pollution impact, the results obtained even for the same problem were also different. Levy et al. ${ }^{[2]}$ conducted their own model of pollution damage function with the calculation results of models proposed by the European Commission (EC), Hagler Bailly (HB) and Oka Ridge National Laboratory and Resources for the Future (ORNL/RFF). In comparison, the environmental impact cost of a single pollutant can be up to 100 times.

In order to conduct a complete LCA analysis, it is also necessary to analyze the environmental impact of the upstream production process of the power plant (ie, the exploitation, processing and transportation of resources, etc.). Levy et al. ${ }^{[2]}$ used a simple estimation method in the analysis: the environmental impact of fuel emissions in the life-cycle stages of the entire production process (Levy only considered health in the calculations) was unchanged, the environmental costs in the upstream production could be determined as long as the ratio of pollutant emissions in the upstream production and the pollutant emissions in the power station production were the same. Levy's estimate of fuel and natural gas blends was that the environmental impact of upstream production would increase the total environmental impact by $28 \%$. Levy argued such an estimate was higher, but it could give a complete cycle analysis. In the LCA analysis of this paper, based on the analysis scope and related assumptions defined in the previous section, the environmental impact costs in the coal mining process also need to be considered.

The final environmental costs will be very different on account of the differences in environmental impact scope, environmental impact factors, statistical items, assumptions, and regional economic and technological development conditions determined in the calculation and analysis. We choose the statistics and the calculation results are used to estimate the macro environmental impact costs per unit of pollutants, because that the purpose of this paper is to analyze the coal power generation technology, the raw materials and products are the same, and there is no need to consider many factors such as the production site and the environmental impact scope. The sources of data are mainly derived from Xia Guang's "Economic Measurement and Research of China's Environmental Pollution Losses"[5] and Zheng Yisheng et al. "Economic Loss Assessment of Environmental Pollution in China: 1993 "[6] and "National Mine Development Ecological Environmental Damage and Reconstruction Survey Report"[7]. The resulting value reflects the extent of pollution across the country.

\subsection{Economic losses caused by solid waste}

In this paper, solid waste refers to the coal gangue produced during the coal mining process and the ash produced during the production of the power station. Environmental damage caused by stacking of solid waste is mainly occupied by land as well as groundwater and soil pollution and dust problems, etc. Due to the lack of 
relevant statistical data in the reference [4][5], the solid waste environmental economic loss estimates have only calculated the land loss of solid waste.

In reference [5], the authors calculated that the area of coal and waste was $920 \mathrm{hm}^{2}$, and the economic loss of land occupation was estimated based on the loss of agricultural income according to the statistical data of the National Environmental Protection Agency in 1992. Taking into account the long-term cumulative loss of land occupation, the increase in land occupation in the current year was $3091 \mathrm{hm}^{2}$. The economic loss was 5.12 billion yuan. The net income of vegetables planted in the Huanghuai region, the middle and lower reaches of the Yangtze River, the south-western region, South China, Beijing, Tianjin and Shanghai prevailed. From this we can estimate the environmental economic loss $\mathrm{CE}_{\text {solid }}$ caused by the accumulation of solid waste per ton in 1992.

$$
\mathrm{CE}_{\text {solid }}=920 \times \frac{51.2}{3091}=15.24
$$

\section{$\mathrm{RMB} /$ tont}

The purchase price of agricultural by-products is to be corrected, and the economic loss of the solid waste environment in 2000 is: $29.31 \mathrm{RMB} /$ tont.

\subsection{Economic losses caused by atmospheric emissions}

In this paper, atmospheric pollution is mainly caused by the atmosphere during the power plant production process emitted harmful substances, including SO2, NOx, and industrial fumes (the environmental impact of $\mathrm{CO} 2$ is separately listed in the analysis below), resulting in major economic losseswhich including loss of human health, agricultural losses, loss of goods and acid rain. According to reference [2-10], We estimate the economic losses caused by the harmful substances emitted by the above atmosphere. The results list in Table 2.

Table 2 Economic Loss Caused by Atmospheric Emissions (2000)

\begin{tabular}{|c|c|c|c|}
\hline \multirow{2}{*}{ Emissions } & \multirow{2}{*}{ environmental impact } & \multicolumn{2}{|c|}{$\begin{array}{c}\text { Environmental Impact } \\
\text { Cost (RMB/kg) }\end{array}$} \\
\hline & & Single item & sum \\
\hline \multirow[b]{2}{*}{ Smoke (dust) } & Human health & 2.18 & \multirow[b]{2}{*}{3.98} \\
\hline & $\begin{array}{l}\text { Loss of articles } \\
\quad \text { (cleaning) }\end{array}$ & 1.80 & \\
\hline \multirow{4}{*}{$\mathrm{SO}_{2}$} & Human health & 0.14 & \multirow{4}{*}{3.73} \\
\hline & Agricultural Production & 0.17 & \\
\hline & Loss of articles & 0.11 & \\
\hline & Acid rain & 3.31 & \\
\hline \multirow{3}{*}{ NOx } & Human health & 0.14 & \multirow{3}{*}{3.38} \\
\hline & Loss of articles* & 0.11 & \\
\hline & Acid rain* & 3.13 & \\
\hline
\end{tabular}

* Assume that NOx causes the same economic loss as SO2 on these two items

\subsection{Economic losses caused by coal mining subsidence}

Land subsidence would lead to ecological destruction, and the biological environment in the ecosystem would reverse drastically, and the organisms in the system would lose the conditions for survival. Finally, crops cannot grow, animals die out or migrate, microorganisms are lost, households relocate, energy flow and material circulation within the system Block, ecological balance damage. The cost of the mine environment reconstruction has been given in the"National Mine Development Ecological Environmental Damage Destruction and Reconstruction Survey Report" ${ }^{\text {[7] }}$. According to the principle of the restoration cost method, the cost of environmental damage is estimated from the cost of environmental reconstruction. The actual reconstruction work cannot be complete. Restore the original environmental conditions, so this estimate is low. The investigation report pointed out that the reconstruction cost for the year 95-96 survey was 113.85 million yuan and the reconstruction area was 32579.1 hectares. The reconstruction cost for one hectare of land was 0.35 million yuan, which was the environmental impact cost caused by land subsidence. Considering the impact of the cpi, the value of the index is 0.68 million yuan per hectare (ie, 0.68 yuan per square meter) in 2000.

\subsection{Economic losses caused by $\mathrm{CO}_{2}$ emissions}

The environmental impact of $\mathrm{CO} 2$ is mainly due to the greenhouse effect. In common greenhouse gases (water vapor, carbon dioxide, methane, ammonia, nitrous oxide, etc.), it is generally believed that $\mathrm{CO} 2$ warms the earth,and the overall effect is greatest among all greenhouse gases,since it had a much longer life span than other gases and emissions are much greater.

The impact of the greenhouse effect is global, leading to an increase in the global average temperature. The resulting impacts are related to agriculture, forestry, water resources, sea level rise and permafrost change. Due to the geographical and climate conditions and ecological conditions of different countries and regions, the ultimate impact of climate change will also be different. Chinese scholars have also studied the impact of changes in atmospheric $\mathrm{CO} 2$ concentration on China's environment. The results showed that: The greenhouse effect would reduce China's agricultural production capacity by at least $5 \%$, lack of large areas of water resources, and some forest production decline; while industrial and agricultural production and livelihoods in high-developed regions such as the Yangtze River, Yellow River and the Pearl River Deltasea were affected by level rise greatly. In addition, serious disasters in permafrost regions in China's frozen soil regions will caused by climate warming. Severe desertification will occur in the plateau permafrost regions phenomenon.

The damage caused by these impacts was wide, and it took a long time for the damage to appear. The relevant economic loss evaluation data was definitely imperfect, and it was difficult to be reflected in the cost analysis of environmental impact. The environmental impact cost of $\mathrm{CO} 2$ in the reference [8] was derived from the 
consideration of human health damage, and was calculated in the same way as the SO2, NOx, and dust estimation methods in the atmosphere. The human health damage cost of $\mathrm{CO} 2$ in China was $0.0003 \mathrm{RMB} / \mathrm{kg}$. Considering the impact of the cpi, the value is 0.0006 $\mathrm{RMB} / \mathrm{kg}$ in 2000.

\section{Conclusion}

According to the above analysis of macro-environmental impact costs in the power plant production life cycle, summarized in Table 3, the final environmental cost for conventional pulverized coal power station production was $0.1419 \mathrm{RMB} / \mathrm{kW} . \mathrm{h}$, and the prices in the table were all converted to values in 2000 .

Table 3 Environmental Costs of Emissions

\begin{tabular}{|c|c|c|c|c|c|}
\hline \multicolumn{2}{|c|}{ Impact factor } & \multirow{2}{*}{$\begin{array}{c}\text { Quantity } \\
0.0974\end{array}$} & \multirow{2}{*}{$\begin{array}{c}\begin{array}{c}\text { Unit } \\
\text { environmental } \\
\text { cost }\end{array} \\
0.029 \\
\mathrm{RMB} / \mathrm{kg}\end{array}$} & \multicolumn{2}{|c|}{$\begin{array}{l}\text { Environmental } \\
\text { cost } \\
(\mathrm{RMB} / \mathrm{kW} . \mathrm{h})\end{array}$} \\
\hline \multirow{2}{*}{$\begin{array}{l}\text { Solid } \\
\text { Waste(kg } \\
\text { /kW.h) }\end{array}$} & $\begin{array}{l}\text { Coal } \\
\text { gangue }\end{array}$ & & & \multicolumn{2}{|c|}{0.0028} \\
\hline & Ash & 0.02857 & $\begin{array}{c}0.029 \\
\mathrm{RMB} / \mathrm{kg}\end{array}$ & \multicolumn{2}{|c|}{0.0008} \\
\hline \multicolumn{2}{|c|}{$\begin{array}{c}\text { Land } \\
\text { collapse }\left(\mathrm{m}^{2} / \mathrm{kW} \cdot \mathrm{h}\right)\end{array}$} & $\underset{3}{0.987 \times 10^{-}}$ & $0.68 \mathrm{RMB} / \mathrm{m}^{2}$ & \multicolumn{2}{|c|}{0.0007} \\
\hline \multirow{4}{*}{$\begin{array}{c}\text { Air } \\
\text { Pollution( } \\
\text { kg/kW.h) }\end{array}$} & $\mathrm{CO}_{2}$ & 0.7690 & $\begin{array}{c}0.0006 \\
\mathrm{RMB} / \mathrm{kg}\end{array}$ & 0.0005 & \multirow{4}{*}{$\begin{array}{c}0.137 \\
6\end{array}$} \\
\hline & $\mathrm{SO}_{2}$ & $\underset{3}{31.43 \times 10^{-}}$ & $3.73 \mathrm{RMB} / \mathrm{kg}$ & 0.1172 & \\
\hline & NOx & $\underset{3}{2.857 \times 10^{-}}$ & $3.38 \mathrm{RMB} / \mathrm{kg}$ & 0.0097 & \\
\hline & Dust & $\underset{3}{2.571 \times 10^{-}}$ & $3.98 \mathrm{RMB} / \mathrm{kg}$ & 0.0102 & \\
\hline
\end{tabular}

It can be seen that there were many uncertainties among them, which made a great difference between the estimated environmental impact costs and the actual effects of emissions from the process of quantification of environmental impacts. SO2, NOx, and dust had a relatively high degree of environmental pollution because of more research and more comprehensive data, and the results were close to the real situation. Whereas, the environmental impact cost of $\mathrm{CO} 2$ is significantly lower because the greenhouse effect is not calculated. The results obtained might be high for the comprehensive utilization of ash residues was not took into account in ash residue estimation; the upstream production process only considered the main impact factors, so the estimated value was low. In addition, according to environmental economics methods, the economic loss of environmental impact is different because of different methods selected by different researchers and the scope of impact determined, such as the estimation results of some pollution in the reference [5-6]. Different estimation results will also affect the environmental impact cost of the plant production.

\section{References}

1. Deng Nansheng, Wang Xiaobin, el. Life Cycle Assessment [M]. Beijing: Chemical industry publishing house, 2003

2. Margaret K. Mann, Pamela L. Spath, China Environmental Science Press, Life Cycle Assessment of Biomass Gasification Combined Cycle Power Generation System, (2000)

3. Jonathan I. Levy, James K. Hammitt, Yukio Yanagisawa, John D. Spengler, Environ. Sci. Technol, Development of a New Damage Function Model for Power Plant: Methodology and Application. Vol.33: 4364 4372 (1999)

4. Zhen puyan, Southeast University doctoral thesis , Coal gasification combined cycle technology, Comprehensive analysis of economic and environmental performance) 2003)

5. Xia guang, China Environmental Science Press, An economic estimation for environmental pollution losses in China,Beijing(1998)

6. Zheng yisheng, Qian yihong, Wang shiwen, Li yujin , Ecological Economy, Assessment of Economic Loss Caused by Environment Pollution in China: 1993, No. 6: 6-14 (1997(

7. Investigation Report on the Destruction and Reconstruction of Ecological Environment in Mine Development China,http://www.sdinfo.net.cn/hjinfo/KD/wbcl/qgk d.thm

8. Robert Caton, Sandy Constable, Clearing the Air: A Preliminary Analysis of Air Quality co-Benefits from Reduced Greenhouse Gas Emissions in Canada, (2000)

9. 1992 China's Environmental Pollution Status Bulletin, Environmental Pollution, http://news.xinhuanet.com/zhengfu/200106/19/content_39332.htm

10. 1993 China's Environmental Pollution Status Bulletin, Environmental Pollution, http://new.xinhuanet.com/zhengfu/20016/19/content_39335.htm 